\title{
NONTHERMAL PLASMA: A REVIEW ON ITS PROSPECTS ON FOOD PROCESSING
}

\author{
Gede Arda ${ }^{1,2 \bowtie, ~ C h u a n-L i a n g ~ H s u ~}{ }^{2}$ \\ ${ }^{1}$ Agricultural Engineering Department, Faculty of Agricultural Technology, Udayana University \\ ${ }^{2}$ The Department of Animal Science, The College of Agriculture, Tunghai University \\ ${ }^{\square}$ Komunikasi Penulis, email: gedearda@unud.ac.id, clh@thu.edu.tw \\ DOI:http://dx.doi.org/10.23960/jtep-l.v9i1.48-54 \\ Naskah ini diterima pada 13 Januari 2020; revisi pada 19 Maret 2020; \\ disetujui untuk dipublikasikan pada 24 Maret 2020
}

\begin{abstract}
Bringing plasma into food processing is a relatively new measure for food engineer and scientist. It is simple in generation, low energy requirement, high efficacy, and easy to apply, pave its way to be a new prospective scenario in processing more safety food recently. Plasma is the fourth matter after solid, liquid and gas contain various reactive species generated by electrical discharge from 10-120kV. Those are Reactive Oxygen and Nitrogen Species (RONS) comprising various reactive species including nitric oxide (NO), superoxide (O2-), hydrogen peroxide (H2O2); singlet oxygen (102); ozone (O3) and even hydroxyl radical (-OH) which can and do play important roles in biological systems. This brief review describes plasma interaction with the biological system and pesticides compound and sums up some finding on the nonthermal application on two main consideration of food safety namely microorganisms decontamination and pesticides residue degradation.
\end{abstract}

\section{Keywords: Non-Thermal Plasma, Microorganisms, Pesticides Residue, Food Safety}

\section{INTRODUCTION}

Postharvest technology is driven from the development achieved by other fields such as biology, chemistry, and physics. Comprehension of fresh produces physiology emerges some technology to maintain their postharvest quality. Refrigerating, the most powerful technology in prolonging fresh produces shelf life among other technology, is based on the concept of reaction velocity which can be deaccelerated by reducing the temperature around the produces. Modified atmosphere storage, packaging technology, coating techniques, are some further technologies which support previous technology, therefore enhance the effectivity of the cooling system. To date, positive effects of cooling technology and or without others technology combination have been reported in various journals including physiology, the functionality of food components, and nutritional point of view.

Produces delivered to consumers not only have a good appearance, high in nutritional content, and good eating quality but also safe from harmful contaminant to their health. Micro bacteria pathogens and pesticides residue, so far, are the sources of produces contaminant. Many outbreaks occur and many victims need to be hospitalized due to food poison. Moreover, Bacillus cereus, one of the suspected microbe as the etiological agent of some food is found 51 percent in vegetables, fruit, and nuts (Kjellander \& Nygren, 1957). Thus postharvest fresh produce handling is conducted to ensure that all produces distributed are risk-free of harmful contaminants and highly contain nutritional value.

Varied techniques have been developed by food scientists and engineers to overcome the problems. there are some very familiar measure applied for food: High-pressure processing (HPP), Pulsed Electric Field processing (PEF), Pulsed light, Ozone Processing (OP), (Rifna, Singh, Chakraborty, \& Dwivedi, 2019). However, these techniques are only adequate for canning processes in factory and cannot be used on fresh fruits and vegetables (Heo et al, 2014). Fresh produce handlers need more convenient methods to be applied. Therefore, the 
introduction of Nonthermal cold plasma technology on food processing and fresh product handling brings new opportunity for postharvest handler to conduct more simple, cheaper, lower energy consumption, and adjustable process (Moreau et al., 2008). However, non-thermal cold plasma have not so mature technology yet that encourage handlers apply the technology in few next years, it need to be explored to enhanced its applicability. This short review presents some scientific background of NTP and describe its potent in econtamination of microorganisms and degradation of agrochemical residues.

\section{PLASMA AND ITS RADICAL OXYGEN SPECIES(ROS) AND RADICAL NITROGEN SPECIES(RNS)}

Plasma is the fourth matter abundantly found in nature, however people need special technology to utilize it. Plasma consist of various radical species playing many roles in living things and non-biological matter process. With its extremely small in size, radical species can be delivered to specific part of biological matter in order to induce desired biological responses. (X. Lu et al., 2016). Reactive Oxygen and Nitrogen Species (RONS) comprising various reactive species including nitric oxide (NO), superoxide $\left(\mathrm{O}_{2}^{-}\right)$, hydrogen peroxide $\left(\mathrm{H}_{2} \mathrm{O}_{2}\right)$; singlet oxygen $\left({ }^{1} \mathrm{O}_{2}\right)$; ozone $\left(\mathrm{O}_{3}\right)$ and even hydroxyl radical $(-$ $\mathrm{OH}$ ) which can and do play important roles in biological systems (Dobrynin et al., 2009). Alteration of macromolecules' (e.g. enzymes) composition and structure lead to alteration of its way to react with other proteins. RONS are known reacts to those kinds of molecules thus it is utilized in such a way to change certain molecules nature, such as molecules involved in oxidation-reduction reaction, immune-response system (X. Lu et al., 2016), even in plant immune response to infection (Frederickson Matika \& Loake, 2014).

The plasma chemistry which is characterised by its excitation, dissociation, and ionisation levels is driven by the electrons, which gain energy from the applied electric field. Due to several orders of difference in mass between the electrons and the heavy particles, the heavy particles can remain at low temperature while undergoing frequent collisions with the energized electrons. The collisions between the energized electrons and the heavy particles result in enhanced levels of excitation, dissociation, and ionization, i.e., enhanced plasma chemistry (XinPei Lu et al., 2008). Application plasma in biomedical field lead to some application in other fields. Due to some plasma advantages have, the method is able to enhance the efficacy of sterilization process. While plasma possibly replace some traditional methods of inactivation of bacteria, its low temperature is suitable to temperature sensitive material treatment (XinPei Lu et al., 2008).

The high concentration and long-time exposure to RONS can be damaging to biological matters since RONS considered as highly reactive species. Combination between those properties describe by (Dröge, 2002) in which the Author suggest that continues high concentration of RONS exposure leads to damaging effects. This damaging effects have two side different perspectives depend on its utilization. On one hand those effects is a helping hands in decontamination of pathogenic microorganisms, thus avoid food from spoiling process faster, on the other hands the effects could result an degradative diseases on human body regard to its effect for long exposure or high concentration of radical species.

Atmospheric Cold Plasma generated by Dielectric Barrier Discharge are potentially applied for biocontroller, mitigation of the presence of chemical residues or other pollutants and degradation of a range of pesticides on cereal (Ziuzina \& Misra, 2016); (Dhayal et al., 2006); (Sarangapani et al., 2017).

\section{PESTICIDE RESIDUE DEGRADATION MECHANISM OF NON-THERMAL PLASMA(NTP)}

Cultivation some needed plant (e.g. vegetables and fruits tree) mean not providing human the food sources they consume but also put host for other creatures such insect, larger animal even micro-organism. The growers compete with those aforementioned creatures, moreover, they 
have to coup with the seasonal change affected the plants. To date, the use of pesticides in modern agricultural practices has enabled the stabilization of crop production patterns globally (Misra, Pankaj, et al., 2014). However, this success does not mean it does not bring other problems. Based on WHO data, approximately 22,000 victims reported death due to single and short-term exposure of pesticides out of $3,000.000$ people. Surprisingly, at least 37,000 people were death due to long-term exposure of pesticides (Jeyaratnam, 1990). Broadly speaking, the number of victims are counted based on the definition of pesticide given by WHO, that is

"a pesticide as any substance or mixture of substances intended for preventing, destroying or controlling any pest, including vectors of human or animal disease, unwanted species of plants or animals causing harm during or otherwise interfering with the production, processing, storage or marketing of food, agricultural commodities, wood and wood products or animal feedstuffs or which may be administered to animals for the control of insects, arachnids or other pests in or on their bodies. The term includes substances intended for use as a plantgrowth regulator, defoliant, desiccant or fruit-thinning agent or agent for preventing the premature fall of fruit and substances applied to crops either before or after harvest to protect the commodity from deterioration during storage and transport" (Food \& Organization, 1986).

Besides, the number of chemical compound used as pesticides so many, by the years of 1964, more than 250 kinds (Magee, 1964) that made the problems become worst.

A contradictory condition faced by people. In one hand the number of people consuming fruits and vegetables is growing, on the other hand the contamination of harmful compound of pesticides on fresh fruits is increasing. Even though some processing steps undergo by food could reduce the pesticide residue (Ling et al., 2011); (Kaushik et al., 2009), consuming fresh fruits or vegetables still remaining a concerns to consumers. Therefore fresh produce handler should find some alternatives to coup the problems.

Recently, non-thermal plasma have been studied in the food processing field for its efficacy on micro-organisms decontamination and on pesticides residue degradation. The application of non-thermal plasma on reducing pesticide residues is encouraged by the fact that some studies found that plasma is able to reduce the residue while it affects the fruit properties insignificantly (Sarangapani et al., 2017); (Schnabel et al., 2015); (Zhou et al., 2018).

Results from (Zhou et al., 2018) proved that plasma is effective in reducing omethoate and dichlorvos from Goji berry (Lycium barbarum) in less than 6 minutes of plasma application (shown by the increment of by-product concentration). From the same study suggested that 30 minutes of plasma application not only reducing those compound but also ensure that degradation intermediates is washed away from berry surface. The study found that reduction of pesticide is obtain through degradation of main-containing compound into other intermediate compound which has a shorter life-time.

There are some factor on which plasma efficacy relied in reducing pesticide residue: working gas of plasma, discharge voltage (kV), duration time, types of treated surface, indirect or direct application of plasma.

Working gas of plasma: the source of plasma determines the radical species produced. Single type of source such as Helium, Argon would not result various radical species. Besides, many kinds of reaction possibly occur in biological matter demands plasma rich in various radical species.

Discharge voltage : discharge voltage determine the power of plasma generator in influencing working gas molecules. The higher the voltage, the richer plasma containing charged, excited, ionized species. (Zhou et al, 2018) reported that the magnitude of discharge voltage significantly affected plasma efficacy. 
Duration time: compared to conventional techniques which using combination of heat and pressure, cold plasma demands a considerably shorter time to treat the product to kill the bacteria. Some research suggest that it needs longer treatment time to degraded agrochemical residues compared to bacteria killing time. The efficacy of plasma is depended on the chance of bacteria or agrochemical being exposed by plasma species, therefore the longer the time the higher its effect The only aspect to be considered in determining treatment time is its effect on product. It is found that $C$ jejuni and ÿbS.typhimurium are inactivated completely in 30 s and 180 s respectively while $P$. fluorescen is inactivated in 90s (Rothrock et al., 2017). A maximum decrease of $69 \%, 45 \%, 71 \%$ and $46 \%$ was observed for azoxystrobin, cyprodinil, fludioxonil, and pyriproxyfen respectively after $300 \mathrm{~s}$ ( 5 minutes) of treatment at $80 \mathrm{kV}(\mathrm{N} . \mathrm{N}$. Misra et al, 2014a); $75 \%$ and $80 \%$ for boscalid and imidacloprid respectively, for 5 minutes application (Sarangapani et al., 2017b).

Types of treated surface: Even though reactive species has an extremely small in size, however some studies reported that the degradationefficiency of plasma on strawberry is lower than on cherry tomato (Misra, Patil, et al., 2014); (Misra, Keener, et al, 2014). The finding suggests that smoother and flatter surface increase plasma efficacy. Besides, organic and inorganic treated surface result in different degree of plasma efficacy.

Direct or indirect application: reactive species generated by plasma discharge will react to substance of product matrix rapidly. Some of those species have very short life-time. Direct application (treated surface are put in plasma region) enable all reactive species generated contribute in sterilization. However, direct exposure to reactive species can disadvantage to physical or chemical properties of fresh product treated. Fortunately, ozone, one of reactive species exist in non-thermal plasma, shows an ability to live longer and contribute in sterilization. Thus, indirect treatment (treated surface are put outside of plasma region) for some reason benefit the product, sterilize the product surface while maintain the quality of the product.

\section{MICRO-ORGANISMS DECONTAMINATION MECHANISM OF NON-THERMAL PLASMA(NTP)}

Some study reported that plasma efficacy on decontaminating micro-organisms depend on the plasma source. Combination of $\mathrm{He} / \mathrm{N}_{2}$ or $\mathrm{He} / \mathrm{O}_{2}$ shows a different result (XinPei Lu et al., 2008). They conclude that the charged particles can deactivate bacteria significantly compare to negative ions. The least role in bacteria deactivation showed by excited particle, plasma heat, and UV.

The mechanisms of plasma decontamination on micro-organism have been broadly review by (Liao et al, 2017). One or several possibility of mechanism could take place when plasma applied to object contaminated by microbes. All the proposed mechanisms are categorized into two ways: biological mechanism and physical mechanism.

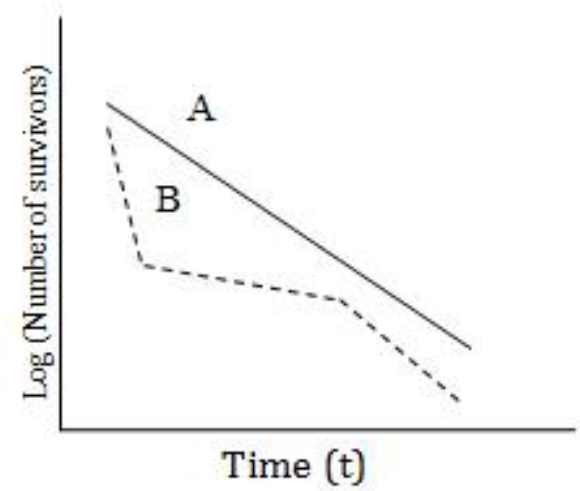

Figure 1. Survival Curve of Bacteria Treated by A. Conventional Sterilization; B. Non-thermal Plasma 
Biological mechanism comprise DNA damage by UV radiation, lipid peroxidation, protein modulation, and inducing apoptosis. Bacteria cell wall are comprised by bilayer network of lipid and protein. This membrane contain poly unsaturated fatty acid (PUFA) which is the most vulnerable against free radical (reactive oxygen species). Once oxygen radical reacts to PUFA, it will activate lipid peroxidation chain reaction and eventually damage the cell wall of bacteria. This damaging reaction occur because hydrogen atom is extracted from PUFA by ROS to form a fatty-acid radical $(\mathrm{L} \bullet)$, which is then finally oxidized into a lipid hydroperoxide (LOOH) by $\mathrm{O}_{2}$ and resulted in shortened fatty acids (Abramzon, Joaquin, Bray, \& Brelles-Marino, 2006) in (Liao et al., 2017). Following mechanism is possible take place after bacteria membrane becomes more fluid, losing its structural integrity due to that lipid peroxidation (Farr' \& Kogoma, 1991). Thus, the bacteria membrane allows ROS to be transported through membrane actively within cells and induce oxidative damage of intracellular components. Recalling the previous authors (XinPei Lu et al., 2008) that UV has not significant role on microbe deactivation compared to other radical species generated by plasma generator, actually underlined by (Liao et al., 2017) in their article. Even though UV is exist in plasma, and it is usually used in microbe decontamination in drinking water, UV's mechanism need more study. There are no contra-argues related to others biological mechanisms found by some researchers included in the same article. Reactive species are easily react to protein which lead to damaging condition to microbe.

Ion and charged particle hold important roles in microbe, therefore imbalance charge between inside and outside lead to cell disruption. Thus, the second mechanism proposed by researcher are electrostatic disruption and electroporation. The former mechanisms leads to cell death due to cell pimple occur when cell are bombard by charged particles. The higher the charge outside the cell, bigger the pimple radius. The cell death occurs when the radius of pimple surpass the tensile strength of cell membrane. The explanation of the later mechanism is derived from Pulsed Electric Field concept. The weak magnetic field force generated by charged particles outside the cell expected increase the mechanical force generated by previous mechanism thus it is raising the disrupting mechanism of charged particles on cell membrane (Liao et al., 2017).

Linearization of microorganisms' survival curves exposed to conventional sterilization process result in a straight line. It means that the rate of killing process of microorganisms is constant. The result is not the same as sterilization using nonthermal plasma by which it could produces 2 or 3 straight survival line. (Moisan et al, 2002). The illustration is presented below (extracted from (Moisan et al., 2002).

\section{CONCLUSION}

The properties of the nonthermal plasma generated by electrical discharge depend on many factor. Therefore, to maturing the application of nonthermal plasma to food processing it is needed more exploration related to generation techniques, effective sources of plasma, and the most important is to comprehend the interaction between plasma and treated object. Even though plasma have not accepted by food industry in large scale, various research have demonstrated that nonthermal plasma possess a bright future for next several years.

\section{REFERENCES}

Dobrynin, D., Fridman, G., Friedman, G., \& Fridman, A. (2009). Physical and biological mechanisms of direct plasma interaction with living tissue. New Journal of Physics, 11(11), 115020. https://doi.org/10.1088/1367-2630/ $11 / 11 / 115020$

Dröge, W. (2002). Free Radicals in the Physiological Control of Cell Function. Physiological Reviews, 82(1), 47-95. https://doi.org/10.1152/ physrev.00018.2001

Food, \& Organization, A. (1986). International code of conduct on the distribution and use of pesticides. na. 
Frederickson Matika, D. E., \& Loake, G. J. (2014). Redox Regulation in Plant Immune Function. Antioxidants \& Redox Signaling, 21(9), 1373-1388. https:// doi.org/10.1089/ars.2013.5679

Jeyaratnam, J. (1990). Acute pesticide poisoning: A major global health problem.

Kaushik, G., Satya, S., \& Naik, S. N. (2009). Food processing a tool to pesticide residue dissipation - A review. Food Research International, 42(1), 26-40. https:// doi.org/10.1016/j.foodres.2008.09.009

Kjellander, J., \& Nygren, B. (1957). B. cereus och fodoamnen. Nord Hyg, 38, 36-45.

Liao, X., Liu, D., Xiang, Q., Ahn, J., Chen, S., Ye, X., \& Ding, T. (2017). Inactivation mechanisms of non-thermal plasma on microbes: A review. Food Control, 75, 83-91. https://doi.org/10.1016/ j.foodcont.2016.12.021

Ling, Y., Wang, H., Yong, W., Zhang, F., Sun, L., Yang, M.-L., Wu, Y.-N., \& Chu, X.-G. (2011). The effects of washing and cooking on chlorpyrifos and its toxic metabolites in vegetables. Food Control, 22(1), 54-58. https://doi.org/10.1016/ j.foodcont.2010.06.009

Lu, X., Naidis, G. V., Laroussi, M., Reuter, S., Graves, D. B., \& Ostrikov, K. (2016). Reactive species in non-equilibrium atmospheric-pressure plasmas: Generation, transport, and biological effects. Physics Reports, 630, 1-84. h t tp s://doi.org/10.1016/ j.physrep.2016.03.003

Lu, XinPei, Ye, T., Cao, Y., Sun, Z., Xiong, Q., Tang, Z., Xiong, Z., Hu, J., Jiang, Z., \& Pan, Y. (2008). The roles of the various plasma agents in the inactivation of bacteria. Journal of Applied Physics, 104(5), 053309. https://doi.org/10.1063/ 1.2977674

Magee, R. J. (1964). Pesticide Literature and Pesticide Research. Journal of Chemical
Documentation, 4(4), 195-196. https:/ /doi.org/10.1021/c160015a001

Misra, N. N., Keener, K. M., Bourke, P., Mosnier, J.P., \& Cullen, P. J. (2014). In-package atmospheric pressure cold plasma treatment of cherry tomatoes. Journal of Bioscience and Bioengineering, 118(2), 177-182. https://doi.org/ 10.1016/j.jbiosc.2014.02.005

Misra, N. N., Pankaj, S. K., Walsh, T., O’Regan, F., Bourke, P., \& Cullen, P. J. (2014). Inpackage nonthermal plasma degradation of pesticides on fresh produce. Journal of Hazardous Materials, 271, 33-40. https://doi.org/ 10.1016/j.jhazmat.2014.02.005

Misra, N. N., Patil, S., Moiseev, T., Bourke, P., Mosnier, J. P., Keener, K. M., \& Cullen, P. J. (2014). In-package atmospheric pressure cold plasma treatment of strawberries. Journal of Food Engineering, 125, 131-138. https:// d o i . o r g / 10 . $1016 /$ j.jfoodeng.2013.10.023

Moisan, M., Barbeau, J., Crevier, M.-C., Pelletier, J., Philip, N., \& Saoudi, B. (2002). Plasma sterilization. Methods and mechanisms. Pure and Applied Chemistry, 74(3), 349-358. https://doi.org/10.1351/ pac200274030349

Moreau, M., Orange, N., \& Feuilloley, M. G. J. (2008). Non-thermal plasma technologies: New tools for biodecontamination. Biotechnology Advances, 26(6), 610-617. https:// d o i . o r g / 10 . $101016 /$ j.biotechadv.2008.08.001

Sarangapani, C., O’Toole, G., Cullen, P. J., \& Bourke, P. (2017). Atmospheric cold plasma dissipation efficiency of agrochemicals on blueberries. Innovative Food Science \& Emerging Technologies, 44, 235-241. https://doi.org/10.1016/ j.ifset.2017.02.012 
Schnabel, U., Niquet, R., Schlüter, O., Gniffke, H., \& Ehlbeck, J. (2015). Decontamination and Sensory Properties of Microbiologically Contaminated Fresh Fruits and Vegetables by Microwave Plasma Processed Air (PPA): Decontamination and Sensory of Food By Plasma. Journal of Food Processing and Preservation, 39(6), 653-662. https://doi.org/10.1111/jfpp.12273

Zhou, R., Zhou, R., Yu, F., Xi, D., Wang, P., Li, J., Wang, X., Zhang, X., Bazaka, K., \&
Ostrikov, K. (Ken). (2018). Removal of organophosphorus pesticide residues from Lycium barbarum by gas phase surface discharge plasma. Chemical Engineering Journal, 342, 401-409. https://doi.org/10.1016/ j.cej.2018.02.107

Ziuzina, D., \& Misra, N. N. (2016). Cold Plasma for Food Safety. In Cold Plasma in Food and Agriculture (pp. 223-252). Elsevier. https://doi.org/10.1016/ B978-0-12-801365-6.00009-3 